\title{
Clinical characterisation and management outcomes of COVID-19 infection in pregnancy in a Nigerian tertiary hospital
}

\author{
Omotade A. Ijarotimi ${ }^{1 *}$, Akaninyene E. Ubom² ${ }^{2}$ Ibraheem O. Awowole', \\ Ekundayo O. Ayegbusi ${ }^{2}$, Oluwafemi Kuti ${ }^{1}$
}

\begin{abstract}
${ }^{1}$ Department of Obstetrics, Gynaecology, and Perinatology, Faculty of Clinical Sciences, College of Health Sciences, Obafemi Awolowo University/Teaching Hospitals Complex, Ile-Ife, Osun State, Nigeria

${ }^{2}$ Department of Obstetrics, Gynaecology, and Perinatology, Obafemi Awolowo University Teaching Hospitals Complex, Ile-Ife, Osun State, Nigeria
\end{abstract}

Received: 03 August 2021

Accepted: 02 September 2021

\section{*Correspondence:}

Dr. Omotade A. Ijarotimi,

E-mail: oijarotimi@cartafrica.org

Copyright: () the author(s), publisher and licensee Medip Academy. This is an open-access article distributed under the terms of the Creative Commons Attribution Non-Commercial License, which permits unrestricted non-commercial use, distribution, and reproduction in any medium, provided the original work is properly cited.

\begin{abstract}
Background: Literature on the antenatal and perinatal management and outcomes of COVID-19 infection in pregnancy in Nigeria and sub-Saharan Africa is gradually emerging but sparse. There is an urgent need to build up the knowledge base of COVID-19 infection in Nigerian pregnant women. The objective of the current study was to determine the clinical characteristics and management outcomes of COVID-19 infection in pregnancy at the Obafemi Awolowo University Teaching Hospitals Complex (OAUTHC), Ile-Ife, Nigeria.

Methods: A one-year retrospective review of all cases of COVID-19 infection in pregnancy managed at the OAUTHC. Relevant data were extracted from the case records of all cases managed using a purpose-designed proforma. Data collected was analysed using IBM-SPSS, version 24. Associations between categorical variables were assessed using chi square, with level of significance set at $<0.05$.

Results: A total of 22 cases were managed. Majority $(15,68.2 \%)$ of the women were either asymptomatic or had mild symptoms. The commonest symptom was cough $(8,36.4 \%)$. The mean duration of admission was $6.6 \pm 4.2$ days. The most common maternal and perinatal complication was preterm delivery/birth $(3,13.6 \%)$. There was no maternal mortality. The mean birth weight of the babies was $3226 \mathrm{~g} \pm 597 \mathrm{~g}$, with mean 1- and 5- minutes Apgar scores of $8.0 \pm 1.3$ and $9.5 \pm 0.6$ respectively.

Conclusions: Although COVID-19 infection in pregnancy is an asymptomatic or mild infection in the majority of cases in Ile-Ife, Nigeria, it is associated with adverse maternal and perinatal outcomes. Further studies are recommended to determine transplacental transmission of COVID-19 infection and antibodies.
\end{abstract}

Keywords: COVID-19, SARS-CoV-2, Pregnancy, Maternal and perinatal outcomes, Nigeria

\section{INTRODUCTION}

In late December 2019, the novel Coronavirus Disease 2019 (COVID-19), caused by SARS-CoV-2, emerged in Wuhan, Hubei province, China. ${ }^{1}$ By 30 January 2020, when the World Health Organisation (WHO) declared COVID-19 as the Sixth Public Health Emergency of International Concern, the disease had spread beyond China, to over 20 countries of the world. ${ }^{1}$ It was subsequently declared a pandemic by the WHO on 11 March 2020, having fulfilled the epidemiological criteria of more than 100,000 infections in at least 100 countries. $^{2}$ To date, a total of over 178 million COVID-19 cases and more than 3.8 million related deaths (case fatality rate (CFR): $2.2 \%$ ) have been recorded globally. ${ }^{3}$ In Nigeria, over 167,000 cases and more than 2,000 related deaths have been recorded since the first case was reported in the country on 27 February $2020 .^{4}$ 
Available data on COVID-19 infection in pregnancy do not show an increased risk of infection in pregnancy, or substantial risk to newborns. ${ }^{5-7}$ However, although pregnant women are not necessarily more susceptible to infection by the virus, changes to their immune system in pregnancy may be associated with more severe symptoms. ${ }^{8}$ Adverse maternal and perinatal outcomes have been reported among pregnant women with COVID-19infection, including maternal pneumonia and maternal death, intrauterine fetal death/stillbirth, preterm birth, neonatal pneumonia/sepsis, disseminated intravascular coagulopathy and neonatal death. ${ }^{9-11}$ Though congenital infection with COVID-19 infection has not been documented, and the virus has not been detected in expelled products of conception, the possibility of vertical transmission exists. ${ }^{6,9,10}$

Literature on the antenatal and perinatal management and outcomes of COVID-19infection in pregnancy in Nigeria and sub-Saharan Africa is gradually emerging, but sparse. ${ }^{8}$ Clinical characterisation of COVID-19 infection in pregnancy is important for prognostication, health care guidelines and policy formulation. The few studies done in Nigeria, though did not document significant association between COVID-19 infection in pregnancy and adverse maternal and perinatal outcomes, did not compare these outcomes with that of the general pregnant population. ${ }^{8,12}$ Treatment modalities were also not elaborated in these studies. There is therefore an urgent need to evaluate the clinical characteristics, and compare maternal and perinatal outcomes of COVID-19 infection in pregnancy with that of the general population of pregnant women in Nigeria, with a view to contributing to the available body of knowledge/evidence in this subject area. This study therefore evaluated the clinical characteristics and management of COVID-19 positive pregnant women at the Obafemi Awolowo University Teaching Hospitals Complex (OAUTHC), Ile-Ife, Nigeria, and compared their perinatal and maternal outcomes with that of COVID-19 negative women in the institution. Recommendations that may improve the care and outcomes of pregnant women with COVID-19 infection were also made. It is expected that findings from this study could inform guidelines that would improve the management and outcomes of pregnant women with COVID-19 infection in the institution, and by extension, Nigeria, and sub-Saharan Africa, thereby reducing maternal and perinatal morbidity and mortality associated with COVID-19 infection in pregnancy. According to the WHO, "all pregnant women have the right to a positive childbirth experience whether or not they have a confirmed COVID-19 infection". ${ }^{13}$

\section{METHODS}

This was a one-year retrospective review of all cases of laboratory-confirmed COVID-19 infection in pregnancy, managed at the OAUTHC, Ile-Ife, Nigeria, between 29 June 2020, when the first case of COVID-19 in pregnancy was confirmed in our hospital, and 29 June
2021. All cases included in the study were confirmed COVID-19 positive using COVID-19 antibody or/and reverse transcriptase polymerase chain reaction (RTPCR) tests. These women were tested either routinely prior to admission for other obstetric indications, based on our hospital/departmental protocol, or/and on clinical suspicion of COVID-19 infection, based on the presence of one or more of the following: a history of self-reported feverishness, cough, loss of sense of smell or/and taste, measured temperature of $\geq 38^{\circ} \mathrm{C}$, dyspnoea, or tachypnoea. Patients were classified into five illness categories based on severity of symptoms viz: asymptomatic, mild, moderate, severe, and critical illness. Patients were said to be asymptomatic if they tested positive for COVID-19, but had no symptoms consistent with COVID-19. Mild illness was characterised by any of the various signs and symptoms of COVID-19 (e.g., fever, cough, sore throat, malaise, headache, muscle pain, nausea, vomiting, diarrhoea, loss of taste and smell), without shortness of breath, dyspnoea, or abnormal chest imaging. Moderate illness was defined as evidence of lower respiratory disease on clinical assessment or imaging, with $\mathrm{SpO} 2 \geq 94 \%$ on room air. Features of severe disease included SpO2<94\% on room air, tachypnoea with respiratory rate $>30$ breaths/min, or $>50 \%$ lung involvement on imaging. Critical symptoms included respiratory failure, septic shock, or/and multiple organ dysfunction. ${ }^{14}$

Relevant data were extracted from the case records of all the patients diagnosed with COVID-19 in pregnancy, using a purpose-designed proforma. The proforma recorded information on the socio-demographic characteristics, clinical characteristics, management, maternal and perinatal outcomes of the cases managed. The extracted data was analysed using the Statistical Package for Social Sciences (IBM-SPSS), version 24. Independent variables included age, marital status, level of education, socioeconomic status, and parity. Dependent or outcome variables were clinical presentation/symptomatology, treatment administered, maternal and neonatal outcomes. The associations between categorical independent and outcome variables were assessed using chi-square, with level of significance set at $<0.05$. The maternal and perinatal outcomes of the COVID-19 positive women were compared with those of COVID-19 negative women delivered in our hospital within the study period.

\section{RESULTS}

\section{Sociodemographic characteristics of pregnant women with COVID-19 infection at the OAUTHC}

Within the study period, a total of 1,074 women were delivered in our facility, of which 22 were COVID-19 positive, giving a prevalence of $2.0 \%$ for COVID-19 infection in pregnancy. The mean age of the women was $30.2 \pm 5.4$ years (range: $23-41$ years). Most of the women had at least secondary education $(17,77.3 \%)$, and 
belonged to the high/middle socioeconomic class $(20$, $90.9 \%$ ). Their parity ranged between $0-4$, with majority of them being multiparous $(10,45.5 \%)$. These sociodemographic characteristics are shown in (Table 1).

Table 1: Sociodemographic characteristics of pregnant women with COVID-19 infection at the OAUTHC, Ile-Ife, Nigeria.

\begin{tabular}{|lll|}
\hline Characteristics & Frequency, $\mathbf{n = 2 2}$ & $\%$ \\
\hline Age (years) & & \\
\hline $20-29$ & 12 & 54.5 \\
\hline $30-39$ & 9 & 40.9 \\
\hline$\geq 40$ & 1 & 4.5 \\
\hline Marital status & & \\
\hline Married & 22 & 100 \\
\hline Level of education & & \\
\hline Primary & 0 & 0 \\
\hline Secondary & 8 & 36.4 \\
\hline Tertiary & 9 & 40.9 \\
\hline Unspecified & 5 & 22.7 \\
\hline Socioeconomic status & \\
\hline High & 10 & 45.5 \\
\hline Middle & 10 & 45.5 \\
\hline Low & 2 & 9.1 \\
\hline Parity & & \\
\hline 0 & 7 & 31.8 \\
\hline 1 & 5 & 22.7 \\
\hline 2 & 7 & 31.8 \\
\hline 3 & 2 & 9.1 \\
\hline 4 & 1 & 4.5 \\
\hline Total & 22 & 100 \\
\hline
\end{tabular}

\section{Clinical characteristics of COVID-19 infection in pregnancy at the OAUTHC}

Table 2 shows that majority $(15,68.2 \%)$ of the women were either asymptomatic or had only mild symptoms. Though not statistically significant, women aged 30 years and above were more likely than those less than 30 years to have severe symptoms $(40 \%$ vs. $25 \%$; $\mathrm{p}=0.520)$. Severe disease was also more prevalent amongst women with comorbidities compared with those without comorbidities $(50 \%$ vs. $25 \% ; \mathrm{p}=0.272)$. The most common comorbidity was hypertensive disorders of pregnancy $(4,18.2 \%)$. All cases of severe disease diagnosed in women with comorbidities were seen in those with hypertensive disorders of pregnancy.

Cough $(8,36.4 \%)$ was the most common symptom, followed by fever, headache, nausea/vomiting, and fatigue $(6,27.3 \%$ each). The least common symptoms were anosmia and sore throat (1, 4.5\% each). Only one patient had an oxygen saturation of $<94 \%$ and required supplemental oxygen. The most common treatment included analgesics and antibiotics (20, 90.9\% each). Other treatment measures are shown in Table 2.
Table 2: Clinical characteristics of COVID-19 infection in pregnancy at the OAUTHC, Ile-Ife, Nigeria.

\begin{tabular}{|c|c|c|}
\hline Characteristics & Frequency, n=22 & $\%$ \\
\hline \multicolumn{3}{|l|}{ Presenting symptoms } \\
\hline Asymptomatic & 10 & 45.5 \\
\hline Cough & 8 & 36.4 \\
\hline Fever & 6 & 27.3 \\
\hline Headache & 6 & 27.3 \\
\hline Nausea/vomiting & 6 & 27.3 \\
\hline Fatigue & 6 & 27.3 \\
\hline Shortness of breath & 5 & 22.7 \\
\hline Joint/body pains & 4 & 18.2 \\
\hline Urinary symptoms & 3 & 13.6 \\
\hline Chest pain & 3 & 13.6 \\
\hline Abdominal pain & 3 & 13.6 \\
\hline Diarrhoea & 2 & 9.1 \\
\hline Bleeding per vaginam & 2 & 9.1 \\
\hline Rhinorrhoea & 2 & 9.1 \\
\hline Anosmia & 1 & 4.5 \\
\hline Sore throat & 1 & 4.5 \\
\hline \multicolumn{3}{|l|}{ Class of symptoms } \\
\hline Asymptomatic & 10 & 45.5 \\
\hline Mild & 5 & 22.7 \\
\hline Severe & 7 & 31.8 \\
\hline \multicolumn{3}{|l|}{ Sp02 at admission $(\%)$} \\
\hline$\geq 94$ & 8 & 36.4 \\
\hline$<94$ & 1 & 4.5 \\
\hline Not done & 13 & 59.1 \\
\hline \multicolumn{3}{|l|}{ Comorbidities } \\
\hline Nil & 16 & 72.7 \\
\hline $\begin{array}{l}\text { Hypertensive disorders } \\
\text { of pregnancy }\end{array}$ & 4 & 18.2 \\
\hline $\begin{array}{l}\text { Gestational diabetes } \\
\text { mellitus }\end{array}$ & 1 & 4.5 \\
\hline Sickle cell anaemia & 1 & 4.5 \\
\hline \multicolumn{3}{|l|}{ Treatment } \\
\hline Analgesics & 20 & 90.9 \\
\hline \multicolumn{3}{|l|}{ Antibiotics } \\
\hline Cephalosporins & 15 & 68.2 \\
\hline Metronidazole & 12 & 54.5 \\
\hline Azithromycin & 3 & 13.6 \\
\hline Ciprofloxacin & 2 & 9.1 \\
\hline Augmentin & 2 & 9.1 \\
\hline Intravenous fluids & 19 & 86.4 \\
\hline \multicolumn{3}{|l|}{ Antimalarials } \\
\hline Chloroquine & 2 & 9.1 \\
\hline Other antimalarials & 9 & 40.9 \\
\hline Dexamethasone & 5 & 22.7 \\
\hline Antiemetic & 2 & 9.1 \\
\hline Anticoagulant & 1 & 4.5 \\
\hline Supplemental oxygen & 1 & 4.5 \\
\hline \multicolumn{3}{|l|}{ Others } \\
\hline Zinc & 3 & 13.6 \\
\hline Ivermectin & 1 & 4.5 \\
\hline
\end{tabular}




\section{Maternal characteristics/outcomes of COVID-19 infection in pregnancy at the OAUTHC}

Most (63.6\%) of the women were diagnosed in the third trimester of pregnancy, with mean duration of admission

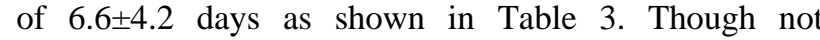
statistically significant, women who had severe disease were more likely than those with asymptomatic/mild disease to spend more days ( $>10$ days) in the hospital (14.3\% vs. 6.7\%; $\mathrm{p}=0.422)$. So also, women with comorbidities compared with those without comorbidities $(16.7 \%$ vs. $6.3 \% ; \mathrm{p}=0.188)$. More than one-half $(13$, $59.1 \%$ ) of the women had caesarean delivery. All the caesareans were for obstetric indications. The majority of the women $(17,77.3 \%)$ had no complication. There were however three preterm deliveries, and two spontaneous miscarriages. Women with comorbidities were significantly more likely than those without comorbidities to suffer maternal complications of COVID-19 infection in pregnancy $(50 \%$ vs. $12.5 \% ; \mathrm{p}=0.044)$. Though not significantly, women with severe disease were also more likely than those with asymptomatic/mild disease to suffer complications (28.6\% vs. 20\%; p=0.057). There was no maternal mortality, and none of the patients required admission into the intensive care unit (ICU).

Table 3: Maternal characteristics and outcomes of COVID-19 in pregnancy at the OAUTHC, Ile-Ife, Nigeria.

\begin{tabular}{|lll|}
\hline Characteristics & Frequency, $\mathbf{n = 2 2}$ & $\%$ \\
\hline Trimester at diagnosis & & \\
\hline First & 4 & 18.2 \\
\hline Second & 3 & 13.6 \\
\hline Third & 14 & 63.6 \\
\hline Puerperium & 1 & 4.5 \\
\hline Duration of admission (days) & 20 & \\
\hline$<10$ & 2 & 90.9 \\
\hline$>10$ & & 9.1 \\
\hline Gestational age at delivery & 3 & \\
\hline Preterm & 17 & 13.6 \\
\hline Term & & 77.3 \\
\hline Mode of delivery & 13 & \\
\hline Caesarean section & 7 & 59.1 \\
\hline $\begin{array}{l}\text { Spontaneous vaginal } \\
\text { delivery }\end{array}$ & 31.8 \\
\hline Complications & 3 & \\
\hline Preterm delivery & 2 & 13.6 \\
\hline Spontaneous miscarriage & 17 & 9.1 \\
\hline Nil & & 77.3 \\
\hline Outcome & 22 & 100 \\
\hline Alive & 22 & 100 \\
\hline Total & &
\end{tabular}

\footnotetext{
Perinatal outcomes of COVID-19 infection in pregnancy at the $\mathrm{OAUTHC}$
}

Out of the 20 delivered mothers, there were 18 singletons and two twin deliveries, giving a total of 22 delivered babies (Table 4). The mean birth weight of the babies was $3226 \mathrm{~g} \pm 597 \mathrm{~g}$, with mean 1- and 5- minutes Apgar scores of $8.0 \pm 1.3$ and $9.5 \pm 0.6$ respectively. Almost threefourth $(16,72.7 \%)$ of the delivered babies had no complication. The most common perinatal complication was preterm birth $(3,13.6 \%)$. Other perinatal complications included birth asphyxia, low birth weight, and stillbirths $(2,9.1 \%$ each). One stillbirth occurred in an unbooked asymptomatic patient with gestational hypertension, who had emergency caesarean delivery at 38 weeks' gestational age, on account of obstructed labour. The baby weighed $4200 \mathrm{~g}$ at birth. The second still birth was seen in a patient with severe COVID-19 symptoms and severe preeclampsia, who had preterm spontaneous vaginal delivery of a macerated female stillbirth, with a birth weight of $2700 \mathrm{~g}$, at 34 weeks' gestation. Severe disease was significantly more associated with adverse perinatal outcomes compared with asymptomatic/mild disease $(42.9 \%$ vs. $20 \%, \mathrm{p}=$ $0.023)$.

Table 4: Perinatal outcomes of COVID-19 infection in pregnancy at the OAUTHC, Ile-Ife, Nigeria.

\begin{tabular}{|c|c|c|}
\hline Characteristics & Frequency, $n=22$ & $\%$ \\
\hline \multicolumn{3}{|l|}{ Sex } \\
\hline Male & 9 & 40.9 \\
\hline Female & 13 & 59.1 \\
\hline \multicolumn{3}{|l|}{ Birth weight (g) } \\
\hline$<2500$ & 2 & 9.1 \\
\hline $2500-4000$ & 18 & 81.8 \\
\hline$>4000$ & 2 & 9.1 \\
\hline \multicolumn{3}{|c|}{ Apgar score at 1 minute } \\
\hline$<7$ & 2 & 9.1 \\
\hline$\geq 7$ & 20 & 90.9 \\
\hline \multicolumn{3}{|c|}{ Apgar score at 5 minutes } \\
\hline$<7$ & 0 & 0 \\
\hline$\geq 7$ & 22 & 100 \\
\hline \multicolumn{3}{|l|}{ Complications $^{\mathrm{a}}$} \\
\hline Nil & 16 & 72.7 \\
\hline Preterm birth & 3 & 13.6 \\
\hline Birth asphyxia & 2 & 9.1 \\
\hline Low birth weight & 2 & 9.1 \\
\hline Stillbirth & 2 & 9.1 \\
\hline \multicolumn{3}{|l|}{ Outcome } \\
\hline Alive & 20 & 90.9 \\
\hline Stillbirth & 2 & 9.1 \\
\hline Total & 20 & 100 \\
\hline
\end{tabular}

Perinatal complications were also seen more significantly in women with comorbidities compared with those without comorbidities ( $50 \%$ vs. $18.8 \%$; $\mathrm{p}=0.005)$. 


\section{Comparison of maternal and perinatal outcomes between COVID-19 Positive and COVID-19 Negative pregnant women at the OAUTHC}

There were significantly more spontaneous miscarriages amongst COVID-19 positive women compared to COVID-19 negative women $(2,9.1 \%$ vs. $17,1.6 \%$; $\mathrm{p}=0.008$ ). Also, though not significantly, there were more stillbirths amongst COVID-19 positive pregnant women compared to negative women $(2,9.1 \%$ vs. $54,4.92 \%$, $\mathrm{p}=0.375)$.

Table 5: Maternal and perinatal outcomes in COVID19 Positive and COVID-19 Negative women at the OAUTHC, Ile-Ife, Nigeria.

\begin{tabular}{|llll|}
\hline & $\begin{array}{l}\text { COVID-19 } \\
\text { positive } \\
\text { women } \\
(\mathbf{N}=22)\end{array}$ & $\begin{array}{l}\text { COVID-19 } \\
\text { Fregative } \\
\text { women } \\
(\text { Ne1,05) }\end{array}$ & $\begin{array}{l}\text { P } \\
\text { value }\end{array}$ \\
\hline $\begin{array}{l}\text { Frequency } \\
(\%)\end{array}$ & \\
\hline $\begin{array}{l}\text { Spontaneous } \\
\text { miscarriage }\end{array}$ & $2(9.1)$ & $17(1.6)$ & 0.008 \\
\hline Stillbirth & $2(9.1)$ & $54^{b}(4.92)$ & 0.375 \\
\hline $\begin{array}{l}\text { Birth } \\
\text { asphyxia }\end{array}$ & $2(9.1)$ & $143^{b}(13.0)$ & 0.584 \\
\hline $\begin{array}{l}\text { Low birth } \\
\text { weight }\end{array}$ & $2(9.1)$ & $232^{b}(21.2)$ & 0.168 \\
\hline $\begin{array}{l}\text { Preterm } \\
\text { birth }\end{array}$ & $3(13.6)$ & $165^{b}(15.1)$ & 0.854 \\
\hline $\begin{array}{l}\text { Maternal } \\
\text { mortality }\end{array}$ & 0 & $3(0.3)$ & 0.802 \\
\hline $\begin{array}{l}\text { No perinatal } \\
\text { complication }\end{array}$ & $16(72.7)$ & $502^{b}(45.8)$ & 0.012 \\
\hline $\begin{array}{l}\text { No maternal } \\
\text { complication }\end{array}$ & $17(77.3)$ & $867^{b}(82.4)$ & 0.532 \\
\hline
\end{tabular}

${ }^{b} \mathrm{n}=1,096$. Of the total of 1,074 deliveries within the study period, there were 1,033 singletons, 38 twins, and three triplets, giving a total of 1,118 delivered babies, out of which 22 were delivered of COVID-19 positive mothers, and 1,096, delivered of COVID-19 negative mothers.

Conversely, more babies delivered to COVID-19 negative mothers were low birth weight $(232,21.2 \%$ vs. $2,9.1 \%)$ and suffered birth asphyxia $(143,13.0 \%$ vs. 2 , $9.1 \%$ ) compared to those delivered to COVID-19 positive mothers. These were however not statistically significant ( $p=0.168$ and 0.584 respectively). Overall, though not significantly, COVID-19 positive status was associated with more maternal complications than COVID-19 negative status $(5,22.7 \%$ vs. $185,17.6 \% ; \mathrm{p}=0.532)$, as depicted on Table 5.

\section{DISCUSSION}

The young, educated, and multiparous demographics of our study population is similarly the finding in other studies. ${ }^{6,12}$
Nearly $50 \%$ of our patients were asymptomatic. This is also the finding in Chinese and other populations. ${ }^{15,16}$ Asymptomatic presentations are common in pregnancy and pose a very high risk of community spread of COVID-19. ${ }^{15}$ Health care personnel providing care to asymptomatic pregnant women are also at significant risk of infection. ${ }^{15}$ The first Nigerian doctor to die of COVID19 was an obstetrician, who contracted the disease following exposure to one of his patients with COVID19. ${ }^{17}$ Most of the patients in our study were diagnosed in the third trimester. This was similarly the finding in another local study. ${ }^{12}$ This finding may not be unconnected with the fact that physiological changes in pregnancy reduce tolerance to hypoxia, especially so in the third trimester. ${ }^{18}$

The most frequent COVID-19 symptoms of cough, fever, headache, nausea/vomiting, and fatigue, reported in our study, have been corroborated by other authors. ${ }^{12,19}$ From our study, severe COVID-19 symptoms were seen more in older women and those with comorbidities, especially hypertensive disorders of pregnancy. COVID-19 infection in older patients and those with underlying medical conditions has a more rapid and severe progression, with worse prognosis, and high mortality rates. ${ }^{20}$ Hypertension is the most common comorbidity found in patients with COVID-19. ${ }^{21}$ The poorer clinical outcomes of COVID-19 infection seen in association with hypertensive disorders may be the direct result of the hypertensive disorder itself, or a secondary effect of coronavirus-induced cardiac dysfunction. ${ }^{20,22}$ Most of the patients in our study were treated with analgesics and antibiotics. The use of analgesics was not unconnected with the fact that headaches, abdominal, joint and body pains were common presentations. Antibiotics reduce complications and mortality by preventing secondary bacterial infections and strengthening immune support treatment, hence their routine use in our patients. ${ }^{9}$ It is recommended that empirical antibiotic regimens for patients with COVID-19 infection should follow local or/and national guidelines. ${ }^{23}$ Antibiotics administered to patients in our study included cephalosporins, metronidazole, azithromycin, augmentin, and ciprofloxacin (used in the women who had miscarriages). This was in line with our local protocol/antimicrobial sensitivity pattern.

Our study corroborated previous studies that found no increased risk of COVID-19 infection in pregnant women. ${ }^{5-7}$ However, from our study findings, COVID-19 infection in pregnancy was associated with adverse perinatal and maternal outcomes. Preterm delivery/birth, the most common maternal/perinatal complication of COVID-19 infection in pregnancy reported in our study, may be a secondary complication of respiratory disease or directly induced by the viral infection. ${ }^{15}$ COVID-19 can cause prelabour rupture of foetal membranes in the third trimester, leading to preterm labour/delivery. ${ }^{18} \mathrm{Zhu}$ et al also postulated that maternal hypoxia caused by COVID-19 can precipitate premature labour. ${ }^{24}$ 
Even though most of the patients in our study had Caesarean delivery, all the Caesareans were for obstetric indications and not due to COVID-19 infection itself. Vaginal delivery in pregnant women with COVID-19 is safe, and has not been found to increase rates of neonatal COVID-19 infection, neonatal or maternal deaths. ${ }^{25}$ Choice of route of delivery should be individualized, and based on obstetric indications vis-à-vis the woman's preference. $^{18,25}$

\section{CONCLUSION}

In conclusion, though pregnant women have not been found to be more susceptible to COVID-19 infection than the general population, and have no significant risk of maternal or/and neonatal complications, from the findings of our study, COVID-19 infection in pregnancy may be associated with adverse maternal and perinatal outcomes including spontaneous miscarriages, preterm birth, birth asphyxia, low birth weight and stillbirths. Older women and those with comorbidities are at higher risk of these adverse maternal and perinatal outcomes, as well as of severe disease. These categories of women should therefore take extra precautions to prevent COVID-19 infection. All pregnant women with COVID19 should be cared for in a tertiary health facility, with close maternal and foetal monitoring, as well as multidisciplinary care. Further studies are recommended to determine transplacental transmission of COVID-19 infection and antibodies.

\section{ACKNOWLEDGEMENTS}

The authors are grateful to the health information management unit of the OAUTHC for granting access to the records of the cases used for this study. Authors thankfully acknowledge the support received by the Consortium for Advanced Research Training in Africa (CARTA).

Funding: No funding sources Conflict of interest: None declared

Ethical approval: The study was approved by the Institutional Ethics Committee

\section{REFERENCES}

1. Wilder-Smith A, Freedman DO. Isolation, quarantine, social distancing and community containment: pivotal role for old-style public health measures in the novel coronavirus (2019-nCoV) outbreak. J Travel Med. 2020;27(2):20.

2. Ohia C, Bakarey AS, Ahmad T. COVID-19 and Nigeria: Putting the realities in context. Int $\mathrm{J}$ Infect Dis. 2020;95:279-81.

3. Outbreak Brief 75: Coronavirus Disease 2019 (COVID-19) Pandemic. Available at: www.africacdc. org. 22 June 2021. Accessed on 30 June 2021.
4. COVID-19 Nigeria. Available at: www.covid19.ncdc. gov.ng. Accessed on 30 June 2021.

5. Chen L, Li Q, Zheng D. Clinical characteristics of pregnant women with Covid-19 in Wuhan, China. N Engl J Med. 2020;382:e100.

6. Zaigham M, Andersson O. Maternal and perinatal outcomes with COVID-19: A systematic review of 108 pregnancies. Acta Obstet Gynecol Scand. 2020; 99:823-9.

7. Schwartz DA. An analysis of 38 pregnant women with COVID-19, their newborn infants, and maternal fetal transmission of SARS-CoV-2: maternal coronavirus infections and pregnancy outcomes. Arch Pathol Lab Med. 2020;45:52-9.

8. Makwe CC, Okunade KS, Rotimi MK, Ekor OE, Oyeleke OG, Bello QO, et al. Caesarean delivery of first prediagnosed COVID-19 pregnancy in Nigeria. Pan Afr Med J. 2020;36:100.

9. Yu N, Li W, Kang Q, Xiong Z, Wang S, Lin X, et al. Clinical features and obstetric and neonatal outcomes of pregnant patients with COVID-19 in Wuhan, China: a retrospective, single-centre, descriptive study. Lancet Infect Dis. 2020;20(5):559-64.

10. Parazzini F, Bortolus R, Mauri PA, Favilli A, Gerli $S$, Ferrazzi E. Delivery in pregnant women infected with SARS-CoV-2: a fast review. Int J Gynaecol Obstet. 2020;150(1):41-6.

11. Chen H, Guo J, Wang C, Luo F, Yu X, Zhang W, et al. Clinical characteristics and intrauterine vertical transmission potential of COVID-19 infection in nine pregnant women: a retrospective review of medical records. Lancet. 2020;395(10226):809-15.

12. Osaikhuwuomwan J, Ezeanochie M, Uwagboe C, Ndukwu K, Yusuf S, Ande A. Clinical characteristics and outcomes for pregnant women diagnosed with COVID-19 disease at the University of Benin Teaching Hospital, Benin City, Nigeria. Pan African Med J. 2021;39:134.

13. Childbirth, breastfeeding, and COVID-19. Available at: https://www.who.int/reproductivehealth/publications/emergencies/COVID-19-pregnancy-ipcbreastfeeding-infographics/en/. Accessed on 30 June 2021.

14. Coronavirus Disease 2019 (COVID-19) Treatment Guidelines. Available at: https://www.covid19 treatmentguidelines.nih.gov/. Accessed on 30 June 2021.

15. Gajbhiye RK, Modi DN, Mahale SD. Pregnancy outcomes, newborn complications, and maternalfetal transmission of SRAS-CoV-2 in women with COVID-19: a systematic review of 441 cases. MedRxiv. 2020;2020:e45215732.

16. Li N, Han L, Peng M, Lv Y, Ouyang Y, Liu K, et al. Maternal and neonatal outcomes of pregnant women with coronavirus disease 2019 (COVID-19) pneumonia: a case-control study. Clin Infect Dis. 2020;71(16):2035-41. 
17. Ijarotimi OA, Ubom AE, Olofinbiyi BA, KuyeKuku T, Orji EO, Ikimalo JI. COVID-19 and obstetric practice: A critical review of the Nigerian situation. Int J Gynaecol Obstet. 2020;151(1):17-22.

18. Rajewska A, Mikolajek-Bedner W, LebdowiczKnul J, Sokolowska M, Kwiatkowski S, Torbé A. COVID-19 and pregnancy- where are we now? A review. J Perinat Med. 2020;48(5):428-34.

19. Pullen MF, Skipper CP, Hullsiek KH, Bangdiwala AS, Pastick KA, Okafor EC et al. Symptoms of COVID-19 outpatients in the United States. Infect Dis. 2020;7(7):271.

20. Sanyaolu A, Okorie C, Marinkovic A, Patidar R, Younis K, Desai P et al. Comorbidity and its impact on patients with COVID-19. SN Compr Clin Med. 2020:1-8.

21. Paudel SS. A meta-analysis of 2019 novel coronavirus patient clinical characteristics and comorbidities. Clin Infect Dis. 2020;70(14):1524-7.

22. W-Jie G, Liang W-H, He J-X, Zhong N-S. Cardiovascular comorbidity and its impact on patients with COVID-19. Eur Respir J. 2020;55:2001227.
23. Sieswerda E, De Boer MG, Bonten MM, Boersma WG, Jonkers RE, Aleva RM, et al. Recommendations for antibacterial therapy in adults with COVID-19- an evidence based guideline. Clin Microbiol Infect. 2021;27(1):61-6.

24. Zhu H, Wang L, Fang C, Peng S, Zhang L, Chang G et al. Clinical analysis of 10 neonates born to mothers with 2019-nCoV pneumonia. Transl Pediatr. 2020; 9:51-60.

25. Cai J, Tang M, Gao Y, Zhang H, Yang Y, Zhang D, et al. Cesarean section or vaginal delivery to prevent possible vertical transmission from a pregnant mother confirmed with COVID-19 to a neonate: a systematic review. Front Med. 2021;8:109.

Cite this article as: Ijarotimi OA, Ubom AE, Awowole IO, Ayegbusi EO, Kuti O.

Clinical characterisation and management outcomes of COVID-19 infection in pregnancy in a Nigerian tertiary hospital. Int J Reprod Contracept Obstet Gynecol 2021;10:3691-7. 